\title{
LIMBAH AIR AC SEBAGAI PELARUT MEDIA SABOURAUD DEXTROSE AGAR (SDA) PADA JAMUR Candida albicans
}

\author{
Victoria Ire Tominik ${ }^{1}$, Margareta Haiti ${ }^{2}$ \\ 1,2Program Studi DIV Teknologi Laboratorium Medik, Unika Musi Charitas Palembang \\ Email: tominikvictoriaire@gmail.com
}

\begin{abstract}
ABSTRAK
Pendahuluan: Indonesia menduduki urutan ketiga dalam insiden dermatomikosis. Candida albicans salah satu jamur yang dapat menginfeksi kulit manusia dan cukup banyak ditemukan di Indonesia. Candida albicans merupakan flora yang bersifat komensal namun bila terjadi perubahan fisiologi pada tubuh pejamu seperti penurunan daya tahan tubuh manusia maka dapat bersifat patogen. Infeksi Candida albicans dapat diketahui melalui pemeriksaan laboratorium. Pemeriksaan laboratorium penting untuk pemberian terapi yang adekuat. Untuk melihat pertumbuhan Candida albicans pada pemeriksaan laboratorium diperlukan pelarut yaitu aquades. Aquades cukup mahal dan kurang mencukupi keberadaannya di laboratorium maka perlu dicari alternatif pengganti yang mempunyai sifat kimia yang sama seperti air AC. Tujuan: mengetahui kemampuan air AC sebagai pelarut media SDA pada jamur Candida albicans. Metode: Jenis penelitian kuasi eksperimen, Posttest Only Control Group Design, menggunakan subyek Candida albicans kelompok aquades 20 sampel dan pelarut air AC 20 sampel dengan tehnik random sederhana. Data dianalisis menggunakan uji komparasi Mann Whitney dengan taraf signifikasi $5 \%$. Hasil : kedua kelompok memiliki nilai median, minimum, maksimum sama dengan rentang nilai rata-rata $\pm S D$ pada kelompok aqudes 10 - $38 \mathrm{CFU} / \mathrm{mL}$ dan kelompok air AC sebanyak 8 - 38 dengan CFU/mL. Uji Mann Whitney-test nilai $p=0,715>0,05$. Simpulan: Kemampuan air AC sebagai pelarut media SDA tidak berbeda dibanding aquades .
\end{abstract}

Kata kunci: Aquades, air AC, Candida albicans, koloni

\section{ABSTRACT}

Introduction: Indonesia ranks third in the incidence of dermatomycosis. Candida albicans is a fungus that can infect human skin and is quite common in Indonesia. Candida albicans is a commensal flora but if there is a physiological change in the host body such as a decrease in human endurance it can be pathogenic. Candida albicans infection can be detected through laboratory examination. Laboratory tests are important for the provision of adequate therapy. To see the growth of Candida albicans in laboratory tests, a solvent is needed, namely aquades. Aquades are quite expensive and are insufficient to exist in the laboratory, so alternative alternatives need to be found that have the same chemical properties as $A C$ water. Objective: to determine the ability of AC water as a solvent in the SDA media on Candida albicans. Method: Quasi-experimental research type, Posttest Only Control Group Design, using the subject Candida albicans group of 20 aquades samples and 20 AC water solvent samples with simple random technique. Data were analyzed using the Mann Whitney comparative test with a significance level of 5\%. Results: both groups had median, minimum, maximum values equal to the average $\pm S D$ range in the aqudes group 10-38 CFU / $m L$ and the AC water group 8-38 with CFU / $m L$. Mann Whitney Test $p$-value $=0.715>$ 0.05. Conclusion: The ability of AC water as a solvent for SDA media is no different from distilled water.

Keywords : Aquades, AC water, Candida albicans, colonies 


\section{PENDAHULUAN}

Indonesia menduduki urutan ketiga dalam insiden dermatomikosis (Soetejo SDR dan Astari L,2016). Candida albicans merupakan salah satu jamur menginfeksi kulit manusia dan cukup banyak ditemukan di Indonesia (Harahap, M. 2000). Candida albican merupakan flora yang bersifat komensal di rongga mulut, saluran pencernaan dan vagina namun apabila terjadi perubahan fisiologi pada tubuh pejamu sehingga berkembang lebih cepat atau adanya penurunan daya tahan tubuh manusia maka akan menggangu sehingga bersifat patogen (Hakim $L$ dan Ramadhian M.R,2015). Menurut Getas I.W, Wiadnya I.B.R dan Wagurian L.A (2014). Candida albicans dapat tumbuh antara $\mathrm{pH} 3$ - 7.

Laboratorium menjadi harapan untuk menegakkan diagnosis infeksi Candida secara tepat kemudian memberikan terapi yang sesuai dan adekuat (Soetejo SDR dan Astari L,2016) sehingga diperlukan melakukan pertumbuhan Candida albicans untuk memastikannya. Dalam kegiatan praktikum dalam laboratorium seperti praktikum kimia, biologi, kegiatan penelitian bahkan laboratorium kesehatan banyak menggunakan aquades. Peraturan Menteri Kesehatan RI No. 43 tahun (2013) yang menyatakan bahwa aquades digunakan untuk pemeriksaan laboratorium kesehatan rutin, penyiapan media mikrobiologi, pewarnaan histologi dan lain-lain.

Wilayah Indonesia merupakan negara dengan iklim tropis dengan lebih dari 17.000 pulau yang terbentang sepanjang garis khatulistiwa dan menurut BMKG wilayah Indonesia mengalami suhu antara 34 sampai 37,5 derajat celcius serta pertumbuhan ekonomi masyarakat Indonesia yang semakin meningkat berdampak semakin meningkat peminat $A C$ di Indonesia
(Fitriana. S, 2019). Persentase menyalakan AC dibawah $25{ }^{\circ} \mathrm{C}$ pada tingkat "sering" rumah tangga di Sumatera Selatan mencapai $48,94 \%$ hal ini lebih tinggi dibandingan dengan persentase nasional sebesar $36,78 \%$ (BPS,2014). Hampir semua gedung perkantoran dan beberapa rumah banyak memakai mesin AC sebagai pendingin ruangan dan air yang dihasilkan dari $A C$ umumnya hanya tergenang dan belum dimanfaatkan secara maksimal (Herison A dkk, 2018).

Menurut Indrawati $\mathrm{T}$ dan Ningsih N.I.D. (2018), menyatakan bahwa Air buangan AC bisa digunakan sebagai pengganti aquades hal ini berdasarkan kesamaan sifat antara air $A C$ dan aquades. Aquades yaitu merupakan hasil air sulingan yang murni dan tidak mengandung kandungan logam-logam ataupun anion, dan mempunyai $\mathrm{pH} 7$ atau netral sementara air dari AC atau limbah AC tidak mempunyai kandungan kation ataupun anion serta mempunyai $\mathrm{pH} 7$ atau netral. Air yang berasal dari AC merupakan hasil kondensasi murni dan besar kemungkinan dapat dimanfaatkan (Hari B.P, Anakorin D, Retno T.M., 2016).

Media pembiakan yang dianggap paling baik dan biasa digunakan salah satunya adalah Sabouraud Dextrose Agar(Gandjar, I., Wellyzar, S., Ariyanti, O. 2006). Menurut Getas I.W, Wiadnya I.B.R dan Wagurian L.A (2014), jamur Candida albicans tumbuh dengan baik menggunakan media SDA (Sabaroud Dextrose Agar). Media kultur yang dipakai untuk biakan $C$. albicans adalah Sabouraud dextrose agar/SDA (Mutiawati. VK,2016).

Tujuan dalam penelitian adalah untuk mengetahui perbedaan jumlah koloni yang tumbuh pada media SDA yang dilarutkan dengan aquades dan air $\mathrm{AC}$ 


\section{METODE PENELITIAN}

Penelitian dilaksanakan pada bulan November 2019, bertempat di Laboratorium Bagian Mikrobiologi, Fakultas IImu Kesehatan UKMC, Palembang. Jenis penelitian ini merupakan kuasi eksperimen dengan Desain penelitian ini adalah Posttest Only Control Group Design, dimana aquades sebagai kelompok kontrol sementara air AC sebagai kelompok perlakuan (Siswanto, 2014). Bahan penelitian adalah Candida albicans yang telah memenuhi kriteria inklusi dan ekslusi sebanyak 25 sampel kelompok pelarut aquades sebagai kelompok kontrol dan 25 sampel pelarut air AC sebagai kelompok perlakuan. Sampel yang digunakan menggunakan rumus Federer (Srigandono, 1981). Sampel sebanyak 20 sampel dari masing - masing kelompok dengan tehnik pengambilan sampel menggunakan random sederhana. Variabel bebas dalam penelitian ini adalah media Sabouraud Dextrose Agar yang dilarutkan dengan aquades dan air $A C$. Variabel terikatnya adalah jumlah koloni jamur Candida albicans. Pembuatan media Sabouraud Dextrose Agar (SDA) yang dilarutkan dengan aquades dan air AC selanjutnya dilakukan uji sterilisasi dan uji kesuburan media (Sonnenwirth et al,1980), uji biakan Candida albicans (Utama, 2012), pembuatan suspensi menyamakan standar Mac Farland No.05 (Cappucino,2013), inokulasi pada media, inkubasi pada suhu $25^{\circ} \mathrm{C}$ selama 48 jam, menghitung jumlah koloni. Analisis data yang dilakukan untuk membandingkan jumlah koloni Candida albicans pada media Sabouraud Dextrose Agar (SDA) yang dilarutkan air $A C$ dan aquades menggunakan uji normalitas Saphiro wilk, uji komparasi Mann Whitney dengan tingkat kemaknaan $\mathrm{p}<0,05$ dengan program statistik komputer.

\section{HASIL}

\section{Uji sterilisasi media}

Hasil uji sterilisasi media yang menggunakan media SDA yang dilarutkan dengan aquades dan air AC didapatkan bahwa kedua kelompok tidak ada pertumbuhan mikroorganisme baik jamur ataupun bakteri, sehingga media yang telah dibuat dapat dinyatakan steril dan dapat digunakan untuk penelitian.

\section{Uji kesuburan media}

Berdasarkan hasil uji kesuburan media maka dapat dinyatakan bahwa media tersebut subur karena jumlah koloni yang tumbuh sesuai dengan inokulum yang ditanam yaitu antara $10-100 \mathrm{CFU} / \mathrm{mL}$.

\section{Uji Strain Biakan Jamur Candida albicans}

Berdasarkan makroskopis dan mikroskopis disimpulkan jamur yang tumbuh dipastikan adalah Candida albicans.

\section{Uji Normalitas Data}

Uji ini dilakukan untuk mengetahui sebaran data normal atau tidak dengan menggunakan uji Saphiro wilk seperti tampak pada tabel 1 berikut :

Tabel 1.

\section{Uji normalitas Saphiro Wilk}

\begin{tabular}{ccc}
\hline $\begin{array}{c}\text { Variabe } \\
\text { I }\end{array}$ & Nilai Sig & Kesimpulan \\
\hline $\begin{array}{c}\text { Aquade } \\
\text { S }\end{array}$ & 0,006 & Tidak Normal \\
Air AC & 0.003 & Tidak Normal
\end{tabular}

Berdasarkan tabel 1 diatas menunjukkan bila sebaran data adalah tidak normal sehingga peneliti melanjutkan menggunakan uji komparasi Mann Whitney 


\section{Analisis Univariat}

Tabel. 2

\section{Nilai Statistik Jumlah Koloni Candida albicans Pada Media SDA dengan Pelarut Aquades dan Air AC}

\begin{tabular}{ccc}
\hline Nilai & $\begin{array}{l}\text { Pelarut } \\
\text { Aquades }\end{array}$ & Pelarur Air AC \\
\cline { 2 - 3 } & $\begin{array}{l}\text { Jumlah koloni } \\
\text { Candida } \\
\text { albicans } \\
(\mathrm{CFU} / \mathrm{mL})\end{array}$ & $\begin{array}{c}\text { Jumlah koloni } \\
\text { Candida } \\
\text { albicans } \\
(\mathrm{CFU} / \mathrm{mL})\end{array}$ \\
\hline Median & 20 & 20 \\
\hline Minimum & 10 & 10 \\
\hline Maksimum & 60 & 60 \\
\hline Rata-rata & 24 & 23 \\
\hline Standar & 14,290 & 14,903 \\
Deviasi (SD) & & \\
\hline
\end{tabular}

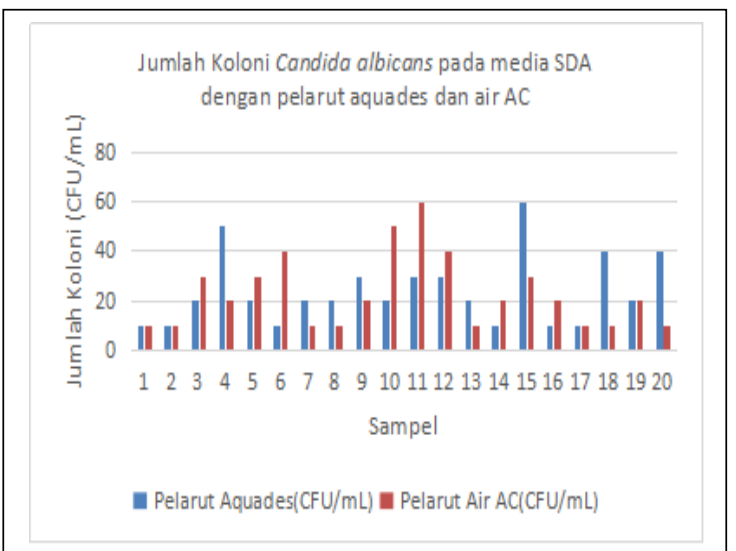

Gambar 1. Histogram Jumlah Koloni Candida albicans Pada Media SDA dengan Pelarut Aquades dan Air AC

Pada tabel 2 dan gambar 1 tampak kelompok pelarut aquades dan air $\mathrm{AC}$ nilai yang sama yaitu nilai median 20 $\mathrm{CFU} / \mathrm{mL}$, nilai minimum $10 \mathrm{CFU} / \mathrm{mL}$ dan nilai maksimum $60 \mathrm{CFU} / \mathrm{mL}$. Rentang nilai rata-rata \pm standar deviasi pada kelompok pelarut aquades sebanyak 10 $38 \mathrm{CFU} / \mathrm{mL}$ dan kelompok pelarut air $\mathrm{AC}$ sebanyak 8 - 38 dengan CFU/mL

\section{Analisis Bivariat}

Berdasarkan hasil uji Mann Whitney-test didapatkan nilai $p=0,715>0,05$ artinya tidak terdapat perbedaan antara jumlah koloni jamur Candida albicans pada media Sabouraud Dextrose Agar (SDA) dengan pelarut aquades dan air AC.

\section{PEMBAHASAN}

Pada penelitian ini didapatkan hasil pada kelompok pelarut aqudes dan air AC. Nilai median (10), nilai minimum (20) dan nilai maksimun (60) sama dengan nilai rata-rata $\pm S D$ kelompok aquades sebanyak 10 - $38 \mathrm{CFU} / \mathrm{mL}$ dan kelompok pelarut air AC sebanyak 8 - 38 dengan $\mathrm{CFU} / \mathrm{mL}$

Menurut Peraturan Menteri Kesehatan RI No. 43 tahun 2013 yang menyatakan bahwa aquades digunakan untuk kultur jaringan atau sel, analisis kimia ultra-mikron, penyiapan larutan standar, dan pelarut media biakan mikrobiologi. Menurut Khotimah et al., (2017), aquades merupakan bahan pelarut utama dalam kegiatan praktikum di laboratorium, bersifat murni, berwarna bening, tidak berbau, dan tidak memiliki rasa. Aquades adalah pelarut yang sangat baik karena berbagai senyawa organik netral yang mempunyai gugus fungsional polar seperti gula, alkohol, aldehida, dan keton cepat larut. Kelarutannya disebabkan karena kecenderungan molekul aquades membentuk ikatan hidrogen dengan gugus hidroksil gula dan alkohol atau gugus karbonil aldehida dan keton (Lehninger, 1982).

Menurut Stoecker menyatakan bahwa Air Conditioning adalah suatu sistem pengkondisian udara dimana udara yang berada di lingkungan dimasukkan ke dalam sistem dan dikondisikan pada suhu yang diinginkan pengguna sementara air $A C$ yang diperoleh berasal dari proses pengembunan akibat adanya suhu udara lebih rendah dari suhu jenuhnya. Air yang berasal dari AC merupakan hasil kondensasi dan besar kemungkinan dapat 
dimanfaatkan (Hari B.P, Anakorin D, Retno T.M., 2016) . Menurut Indrawati T dan Ningsih N.I.D. (2018), berdasarkan kesamaan sifat antara air AC dan aquades, maka dapat dinyatakan bahwa air AC dapat digunakan sebagai pengganti aquades dimana sifat dari aquades yaitu merupakan hasil air sulingan yang murni dan tidak mengandung kandungan logam-logam ataupun anion, dan mempunyai $\mathrm{pH} 7$ atau netral sementara Air dari $A C$ atau limbah AC tidak mempunyai kandungan kation ataupun anion serta mempunyai $\mathrm{pH} 7$ atau netral.

Menurut Safitri dan Novel (2010) media Sabouraud Dextrose Agar (SDA) sangat baik untuk pertumbuhan mikroorganisme, salah satunya adalah jamur Candida albicans dan tumbuh pada suhu $37^{\circ} \mathrm{C}$ selama 48 - 72 jam. Sabouraud Dextrose Agar (SDA) adalah media suplemen pepton dengan dextrose digunakan untuk membantu pertumbuhan jamur. Pepton sebagai sumber nitrogen yang digunakan pada medium ini berupa dextrose yang akan menjadi sumber energi untuk pertumbuhan jamur (Difco ${ }^{\mathrm{TM}}$ dan BBL ${ }^{\mathrm{TM}}$ Manual, 2009).

Menurut peneliti, media SDA yang mengandung komposisi gula (dextrose) merupakan media yang cocok untuk pertumbuhan jamur Candida albicans sehingga bila bertemu dengan air $A C$ mampu bereaksi sama dengan aquades dimana membentuk ikatan hidrogen sehingga senyawa menjadi segera melarut. Hal ini disebabkan air AC mempunyai sifat yang hampir sama dengan aquades terbukti hasil analisis univariat antara aquades dan air AC mempunyai nilai median, nilai minimum dan maksimum yang sama serta rentang rata-rata $\pm S D$ kelompok aquades dan air AC hampir mendekati yaitu kelompok pelarut aquades sebanyak 10 - 38 $\mathrm{CFU} / \mathrm{mL}$ dan kelompok pelarut air $\mathrm{AC}$ sebanyak 8 - 38 CFU/mL. Hasil analisis secara bivariat memperkuat pendapat peneliti dengan hasil uji statistik Mann Whitney dengan nilai sig 0,715 >0,05 yang artinya tidak adanya perbedaan jumlah koloni dari kedua pelarut tersebut. Artinya kemampuan air AC sebagai pelarut media SDA tidak berbeda dengan kemapuan aquadest.

\section{SIMPULAN}

Berdasarkan uji statistik menyimpulkan bahwa kemampuan air AC sebagai pelarut media SDA pada jamur Candida albicans tidak berbeda dengan aquadest.

\section{SARAN}

Perlu dilakukan penelitian lebih lanjut tentang komposisi biokimia sehingga dketahui lebih dalam yang mempengaruhi pertumbuhan koloni.

\section{DAFTAR PUSTAKA}

1. BPS. 2014. Persentase Rumah Tangga yang Memiliki AC Menurut Provinsi dan Perilaku Menyalakan AC Dibawah 250C, 2013 .[Online] https://www.bps.go.id/statictable/2014 105/02/1355/persentase-rumahtangga-yang-memiliki-ac-menurutprovinsi-dan-perilaku-menyalakan-acdibawah-25-c-2013.html. [Diakses 16 Juli 2019].

2. Cappucino, J., \& Sherman, N. (2013). Manual Laboratorium Mikrobiologi. Jakarta: EGC.

3. Dahlan SM (2012). Statistik Untuk Kedokteran Dan Kesehatan. Jakarta: EGC

4. Difco, \& BBL. (2009). Manual of Microbiological Culture Media. USA: Becton, Dickinson and Company.

5. Fitriana S. 2019. Analisis Menentukan Rekomendasi Penyejuk Udara Yang Tepat Menggunakan Metode Moora. 
Jurnal Evolusi. Volume 7 Nomor 1 $2019: 89-95$

6. Gandjar, I., Wellyzar, S., Ariyanti, O. 2006. Mikologi Dasar dan Terapan. Jakarta : Yayasan Obor Indonesia.

7. Getas I.W, Wiadnya I.B.R dan Wagurian L.A. 2014. Pengaruh Penambahan Glukosa Dan Waktu Inkubasi Pada Media SDA (Sabaroud Dextrose Agar) Terhadap Pertumbuhan Jamur Candida Albicans. Media Bina Ilmiah S1. Volume 8 Nomor 1 Februari 2014 : $51-56$.

8. Hakim $L$ dan Ramadhian M.R. 2015.Kandidiasis oral. Majority Vol.4 No.8 Desember 2015: 53 - 57

9. Harahap, M. 2000. Ilmu Penyakit Kulit. Jakarta : Hipokrates

10. Hari B.P, Anakorin D, Retno T.M.2016. Studi Pemanfaatan Kondensat Air Conditioning (AC) Menjadi Air Layak Minum.Prosiding Seminar Nasional Tehnik Kimia Kejuangan Yogyakarta.17 Maret 2016. ISSN 1693-4393

11. Herison A, dkk, 2018. Kajian Penggunaan Kondensat AC Sebagai Bahan Baku Air Minum Dari Segi Kualitas Dan Kuantitas (Review). Jurnal Spatial. Volume 18 Nomor 1 2018: $14-23$.

12. Indrawati T dan Ningsih N.I.D.2018. Penerapan Statistik Proses Control Dalam Pengamatan Sifat Fisika Dan Kimia Air Buangan Dari Air Conditioning (AC). Integrated Lab Jurnal Volume 06 Nomor 02 Oktober $2018: 85-92$.

13. Khotimah $\mathrm{H}$, Anggraeni. E.W, dan Setianingsih A. 2017. Karakterisasi Hasil Pengolahan Air Menggunakan Alat Destilasi. Jurnal Chemurgy Volume 1 Nomor 2 Desember 2017 : $34-39$.
14. Lehninger. 2008. Dasar-Dasar Biokimia, terj. Maggy Thenawidjaja. Jakarta: Erlangga.

15. Mutiawati V.K.2016. Pemeriksaan Mikrobiologi Pada Candida albicans. Jurnal Kedokteran Syiah Kuala. Volume 16 Nomor 1 Agustus 2016 : $53-63$.

16. Republik Indonesia.2013. Peraturan Menteri Kesehatan Nomor 43 tahun 2013. Cara Penyelenggaraan Laboratorium Klinik Yang Baik.Jakarta

17. Safitri, R., \& Novel, S. S. (2010). Medium Analisis Mikroorganisme (Isolasi dan Kultur). Jakarta: CV. Trans Info Media.

18. Siswanto, Susila, Suyanto. 2014. Metode Penelitian : Kesehatan dan Kedokteran. Yogyakarta : Bursa IImu. 2014.

19. Soetojo SDR dan Astari L,2016. Profil Pasien Baru Infeksi Kandida pada Kulit dan Kuku. BIKKK Volume 28 Nomor 1. April $2016: 34-41$.

20. Sonnenwirth AC, Jarett L (1980). Gradwohl's Clinical Laboratory Methods and Diagnostic. United State Of America : Mosby Company.p: 1482.

21. Srigandono, B. 1981. Rancangan Percobaan (Eksperiment Design). Universitas Diponegoro, Semarang. HIm 23-26.

22. Stoecker F. Wilbert :Jones, J.W dan Supratman H. 1996. Refrigerasi dan Pengkondisian Udara. Edisi 2. Erlangga. Bandung.

23. Utama, H. (2012). Praktikum Mikrobiologi Kedokteran. Jakarta: Badan Penerbit FKUI. 